Fuzzy sets and fuzzy logic in multi-criteria decision making. The 50th anniversary of prof. Lotfi Zadeh's theory

\title{
SMALL HYDRO-POWER PLANT PROJECT SELECTION USING FUZZY AXIOMATIC DESIGN PRINCIPLES
}

\author{
Anant V. KHANDEKAR ${ }^{\mathrm{a}}$, Jurgita ANTUCHEVIČIENÉ ${ }^{\mathrm{b}}$, \\ Shankar CHAKRABORTYc \\ ${ }^{a}$ Department of Mechanical Engineering, Government Polytechnic, Bandra (East), \\ 400051 Mumbai, Maharashtra, India \\ ${ }^{b}$ Department of Construction Technology and Management, Vilnius Gediminas Technical University, \\ Sauletekio al. 11, LT-10223 Vilnius, Lithuania \\ ${ }^{c}$ Department of Production Engineering, Jadavpur University, 700032 Kolkata, West Bengal, India
}

Received 30 March 2015; accepted 17 May 2015

\begin{abstract}
There has been a rapid growth in construction activities during the last few decades owing to overall development in all facets of humanity. Due to technological advancements and ever increasing civilization, there is a persistent need of energy. Along with the conventional energy sources, the renewable energy sources have also significantly contributed to the rising energy needs. As a renewable source of energy, numerous small hydro-power plants (SHPPs) have been built up across the world in the recent past. Usually these SHPPs are being built and operated by the private developers complying with the government regulations. In order to assist a developer in selecting the most profitable and feasible SHPP for construction and subsequent operation, a method based on fuzzy axiomatic design principles is employed in this paper. The techno-commercial and socioeconomic criteria as considered for analyzing the feasibility of the candidate SHPPs are expressed qualitatively using trapezoidal fuzzy numbers. The performance of each SHPP is evaluated in terms of its total information content and the one with the least information content is selected to be the best venture for the required construction activity. The adopted methodology is found to have immense potential to the developers while selecting the most feasible project for construction.
\end{abstract}

Keywords: axiomatic design principles, fuzzy set theory, information content, small hydro-power plant (SHPP), project selection.

JEL Classification: C63, D81, O22, Q42.

\section{Introduction}

Globally electric power requirement is constantly increasing due to the rise in population, and corresponding escalation in industrial and agricultural activities. Broadly, electric power is generated from two types of energy sources, i.e. conventional and non-conventional.

Corresponding author Jurgita Antuchevičienè

E-mail: jurgita.antucheviciene@vgtu.lt 
Conventional or non-renewable energy sources, such as coal, natural gas, fossil fuel or oil, nuclear fission etc. are widely used for power generation and account for a greater part with respect to the total installed generation capacity. On the other hand, renewable energy sources include geothermal, biomass, wind energy, solar energy, hydro-power, and so on. The electricity generation from renewable energy sources accounts for a smaller amount with respect to the total installed generation capacity and this sector needs to be strongly focused for the sustainable development of energy scenario. Hydro-power is one of the important renewable energy sources in the total volume of electricity generated worldwide and accounts for about $24 \%$ of the total energy production (Contreras et al. 2012). This hydro-power potential is only partially exploited and hence, possibilities are being explored for its complete utilization through construction of SHPPs (Panić et al. 2013).

Generally, hydro-power projects are classified into two categories, i.e. small hydro-power plant (SHPP) and large hydro-power plant (LHPP), based on the power generation capacity. SHPP refers to a hydroelectric plant with less than $25 \mathrm{MW}$ of generation capacity and is typically of canal-based or run-of-the river type. On the other hand, LHPP refers to a plant with a generation capacity greater than $25 \mathrm{MW}$ and is generally associated with a large dam built up across a river. SHPPs are further classified as follows: micro hydro-power plant - up to $100 \mathrm{~kW}$; mini hydro-power plant - $101 \mathrm{~kW}$ to $2 \mathrm{MW}$; and small hydro-power plant - $2 \mathrm{MW}$ to $25 \mathrm{MW}$.

Some distinct advantages can be attributed to SHPPs, such as ability to generate clean energy at a competitive price, suitability for peaking operations, less affected by rehabilitation and resettlement problems being environmentally benign as against LHPPs, ability to meet the power requirements of remote and isolated areas, use of largely indigenous technology requiring a relatively shorter time for implementation and so on. Also, by virtue of construction of hydro-power plants, the society in general is benefitted by the concomitant development of the potable and industrial water supply systems, expansion of boat traffic, development of irrigation systems and regulation of the river run-off which helps to control high waters and flooding.

Against the advantages as mentioned above, hydro-power plants also bring with them some negative aspects of social and environmental nature. In general, construction of hydro-power plants directly affects the local communities and environment. Diverse factors, like water flow, water shed management, habitat protection of concerned livestock, and welfare and lifestyle of the local communities are taken into consideration as part of the environmental impact assessment of hydro-power plants (Zelenakova et al. 2013). Still, the advantages far outweigh the shortcomings, and hence, it is always logical to explore more and more SHPPs.

In the case of India, according to a recent report from an investment information and credit rating agency (ICRA), India's total installed capacity for SHPPs is about $3500 \mathrm{MW}$ and it amounts for only $15 \%$ of the country's total installed renewable energy capacity. To boost up the construction activity of SHPPs, in accordance with the liberalized economic policy of Government of India in 1995, the manufacturing base for SHPP equipment is strengthened and the private sector participation is allowed to exploit the full potential of SHPPs. Nevertheless, considerable opportunity still remains untapped across the Indian 
states having favourable small hydro-power potential. In this paper, four SHPPs with designed generation capacity of $25 \mathrm{MW}$ are identified for final evaluation and selection. Since the capital investment cost for setting up a SHPP of $25 \mathrm{MW}$ generation capacity is as high as Rs. 2 billion (33 million USD), the concerned private developer thus faces the problem of selecting the most profitable and feasible SHPP for commencing the construction activity.

Construction of a SHPP is characterized by many dependent criteria, like availability of water potential, suitability of site for construction, fulfilment of government rules and regulations, prevalent political situation, local socio-economic issues and so on. At times, the concerned criteria are in conflict with each other and hence to take a proper decision of selecting the best SHPP construction project becomes an uphill task. In the current paper, a total of seven criteria, expressed qualitatively, are considered for describing the status of four SHPP construction projects. A methodology based on fuzzy axiomatic design principles (FAD) is then applied to evaluate and rank those projects.

In the later part of the current paper, the relevant literature regarding selection of construction projects of various types is reviewed in Section 1. The FAD methodology is described in Section 2. The proposed approach based on FAD methodology is presented in Section 3. A representative problem of SHPP project selection is solved in Section 4, followed by the concluding remarks in the last section.

\section{Literature survey}

There exists a few literatures specifically on the topic of construction project selection as against the generalized topic of project selection and here it is summarized briefly. Cheng and Li (2005) developed a five-level project selection model based on analytic network process (ANP) to prioritize a set of construction projects based on some identified and weighted criteria. In an illustrative example, six construction projects were evaluated with respect to a set of pivotal criteria, like operational, managerial, financial, technological, legal and environmental factors. Han et al. (2005) investigated the risk attitude and bid decision behaviour in the selection process of international construction projects. Dey (2006) analyzed the construction projects with respect to market, technicalities, social and environmental impacts in an integrated framework using analytic hierarchy process (AHP). The effectiveness of the proposed methodology was validated while demonstrating its application to a cross-country oil pipeline project in India. Puthamont and Charoenngam (2007) considered the strategic selection procedure of military infrastructure projects under the Ministry of Defense of Thailand with an in-depth understanding of various factors influencing the three stages of construction project selection process, e.g. conceptual stage, design stage and final approval stage. As a pre-requisite stage for final construction project selection decision, Wang et al. (2009) developed a methodology for design project bidding based on the evaluation models using logical valuation and grey target methods. Mojahed et al. (2010) recognized a total of 27 criteria for construction project selection while using Delphi method and ranked those criteria according to their weighting coefficients. Chen et al. (2011) developed a project delivery system selection model 
for construction projects in China using artificial neural network and data envelopment analysis techniques. Hernández et al. (2011) adopted a portfolio management approach for construction project selection decisions. A new value-based indicator, "Project Value to Portfolio Value" was defined to assess the added value of a new project to the value of the firm's actual portfolio of projects. KarimiAzari et al. (2011) developed a group-based fuzzy technique for order performance by similarity to ideal solution (TOPSIS) approach with an effective algorithm to select a suitable risk assessment model for construction projects. Ebrahimnejad et al. (2012) proposed a new two-phase group decision-making approach consisting of a modified ANP and an improved compromise ranking method, known as Vlse Kriterijumska Optimizacija Kompromisno Resenje (VIKOR), for construction project selection. Rouyendegh (2012) applied intuitionistic fuzzy TOPSIS method for construction project selection while considering some important criteria as net present value, quality, duration, contractor's rank, contractor's technology and contractor's economic status. Zavadskas et al. (2013) presented application of weighted aggregated assessment (WASPAS) and multiple objective optimisation on the basis of ratio analysis plus full multiplicative form (MULTIMOORA) methods for assessment of alternative building designs based on criteria representing structural and physical, as well as ecological-economical properties of alternatives. Weissenböck and Girmscheid (2014) proposed the concept of a new quantitative model to guide the project selection process of large international construction companies, while using public private partnership project as an example. Naaranoja et al. (2014) considered construction projects as the research objects and focused on the possible contributions of different scientific approaches used in research efforts where the researchers could act as change makers based on the research data accumulated from the experiments. Rejment and Dziadosz (2014) focused on the selection of construction projects with respect to their risk estimation, which would be always there for realization of a particular construction project. Various primary risk factors, such as economic risk, contract risk, organizational risk, technical risk along with other related sub-factors were considered and two multi-criteria decision-making methods as AHP and COmplex PRoportional ASsessment of alternatives with grey relations (COPRAS-G) were employed for subsequent analysis. Group decision making methods for mining projects were applied by Rikhtegar et al. (2014). Taylan et al. (2014) analyzed 30 construction projects with respect to five main criteria as time, cost, quality, safety and environment sustainability while applying fuzzy AHP and fuzzy TOPSIS methodologies in an integrated manner. In the research of Zavadskas et al. (2014) construction project performance indicators also were analysed and the aggregated criterion was calculated by applying methods of multiple criteria analysis. Recently increasing attention is given to renovation projects in terms of selecting the best multi-flat residential buildings renovation alternative according to technological, economic and ecological aspects (Staniūnas et al. 2013), or selecting the most suitable upgrading decision for historic or vernacular buildings taking into account their heritage value (Vodopivec et al. 2014; Turskis et al. 2013; Siozinyte et al. 2014). In the case of energy projects, Streimikiene (2013) assessed energy technologies with the help of interval TOPSIS method. Bagocius et al. (2014) analysed projects for green energy production and proposed to assess 
the type of wind turbines as well as their location in the Baltic Sea offshore area by applying WASPAS and permutation methods. Wu et al. (2014) applied a three phase methodology for evaluation and selection of the best plan for a wind farm project of $200 \mathrm{MW}$ generation capacity in the northwest region of China. Various criteria and sub-criteria based on qualitative, economic, environmental, risk and contribution merits were considered, and intuitionistic fuzzy choquet operator and generalized intuitionistic fuzzy ordered geometric averaging operator were employed to deal with the compensatory performance scores and non-compensatory performance scores respectively.

From this review of literature, it becomes quite evident that in the past decade, the quantum of research in the field of construction project selection is not in proportion with the tremendous spurt in the construction activities in various fields. This may be attributed to the specificity, complexity, uniqueness and most of the times to the mega scale nature of the construction projects in general. It can also be observed that most of the factors influencing the commencement of any construction project are imprecise and vague in nature. Therefore, the application of FAD methodology for analysis and selection of SHPP construction projects can be justified against the backdrop of uncertainty and impreciseness of the governing factors.

\section{Fuzzy axiomatic design principles}

Axiomatic design (AD) forms the basis of a design model for systematic, scientific, and logical design of any product in general. It is fundamentally based on recognizing the ultimate product attributes to be realized in the product. These product attributes are nothing but the customers' requirements and are termed as functional requirements (FRs) in AD terminology (Suh 1990). In order to satisfy these FRs effectively, the said product should possess the corresponding features, known as design parameters (DPs). The process of design using $\mathrm{AD}$ principles is supported by two underlying axioms.

\subsection{Independence axiom}

This axiom highlights the necessity to maintain the independence of FRs. In other words, for good design of a product, it should be ensured that a certain FR is fulfilled completely and effectively by the corresponding single DP, without affecting the other FRs. Mathematically, the relationship between FRs and DPs can be expressed as follows:

$$
\{F R\}=[A]\{D P\}
$$

where $\{F R\}$ is the functional requirement vector, $\{D P\}$ is the design parameter vector and $[A]$ is the design matrix that characterizes the design. Let us explore a design problem with three number of FRs and DPs each. The structure of design matrix defines the nature of the design problem. As shown in Eq. (2), if the design matrix is a diagonal matrix (except the diagonal elements, all the elements are zero), it is an uncoupled design which perfectly satisfies the independence axiom because each DP can satisfy a corresponding FR. When the design matrix is triangular (upper or lower), as shown in Eq. (3), the design is a decoupled 
design. A decoupled design satisfies the independence axiom if the design sequence is correct. Under this circumstance, $\mathrm{DP}_{1}$ is first determined for $\mathrm{FR}_{1}$ and fixed. $\mathrm{FR}_{2}$ is satisfied by the choice of $\mathrm{DP}_{2}$ and the already fixed $\mathrm{DP}_{1}$. Then, $\mathrm{FR}_{3}$ is satisfied by $\mathrm{DP}_{3}$, provided that $\mathrm{DP}_{1}$ and $\mathrm{DP}_{2}$ are fixed beforehand. As shown in Eq. (4), when a design matrix is neither diagonal nor triangular, the design becomes a coupled design in which FRs are unable to be satisfied independently by any sequence of DPs:

$$
\begin{aligned}
& {\left[\begin{array}{l}
F R_{1} \\
F R_{2} \\
F R_{3}
\end{array}\right]=\left[\begin{array}{ccc}
A_{11} & 0 & 0 \\
0 & A_{22} & 0 \\
0 & 0 & A_{33}
\end{array}\right]\left[\begin{array}{l}
D P_{1} \\
D P_{2} \\
D P_{3}
\end{array}\right] ;} \\
& {\left[\begin{array}{l}
F R_{1} \\
F R_{2} \\
F R_{3}
\end{array}\right]=\left[\begin{array}{ccc}
A_{11} & 0 & 0 \\
A_{21} & A_{22} & 0 \\
A_{31} & A_{32} & A_{33}
\end{array}\right]\left[\begin{array}{l}
D P_{1} \\
D P_{2} \\
D P_{3}
\end{array}\right] ;} \\
& {\left[\begin{array}{l}
F R_{1} \\
F R_{2} \\
F R_{3}
\end{array}\right]=\left[\begin{array}{lll}
A_{11} & A_{12} & A_{13} \\
A_{21} & A_{22} & A_{23} \\
A_{31} & A_{32} & A_{33}
\end{array}\right]\left[\begin{array}{l}
D P_{1} \\
D P_{2} \\
D P_{3}
\end{array}\right] .}
\end{aligned}
$$

\subsection{Information axiom}

The design solutions satisfying the first axiom (independence axiom) are further analyzed by the second axiom, i.e. the information axiom. According to this axiom, the information content (IC) of each alternative design solution is determined and the alternative with the minimum IC value is treated as the optimal choice (Suh 2001). The IC value is related in its simplest form to the probability of satisfying a given FR. It determines that the design with the highest probability of success is the best design. The $I C_{i}$ value for a given $\mathrm{FR}_{i}$ is defined using the following equation:

$$
I C_{i}=\log _{2}\left(\frac{1}{p_{i}}\right),
$$

where $p_{i}$ is the probability of satisfying the functional requirement $\mathrm{FR}_{i}$. The information is expressed in units of bits. The logarithmic function is chosen so that the $I C$ values are additive when there are many FRs that must be satisfied simultaneously and the logarithm is based on 2 which is the unit of bits.

In $\mathrm{AD}$ methodology, FRs are generally expressed in terms of range of values. The ideal range of values, as decided by the designer or decision maker for different criteria, is known as design range (DR). On the other hand, the capability of a considered alternative to satisfy a given criterion is called as system range (SR). The probability of having a successful design is governed by the relative values of DR and SR. An acceptable design solution exists in the region of common range (CR) where DR and SR overlap as depicted in Figure 1.

In case of uniform probability distribution function, $p_{i}$ can be formulated as follows:

$$
p_{i}=\left(\frac{\mathrm{CR}}{\mathrm{SR}}\right) \text {. }
$$




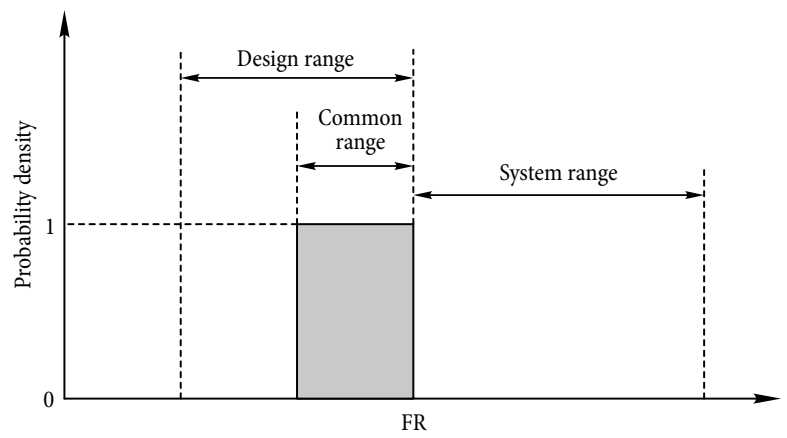

Fig. 1. Design range, system range and common range for FR

So, the value of IC can now be expressed as below:

$$
I C_{i}=\log _{2}\left(\frac{\mathrm{SR}}{\mathrm{CR}}\right) .
$$

If $\mathrm{FR}_{i}$ is a continuous random variable, as shown in Figure 2, then the probability of achieving $\mathrm{FR}_{i}$ in $\mathrm{DR}$ is given as follows:

$$
p_{i}=\int_{d r^{l}}^{d r^{u}} p_{s}\left(\mathrm{FR}_{i}\right) d \mathrm{FR}_{i},
$$

where $p_{s}\left(\mathrm{FR}_{i}\right)$ is the system probability density function (pdf) of $\mathrm{FR}_{i}$. $d r^{l}$ and $d r^{u}$ are the lower and upper bounds of DR. The probability of success is calculated by integrating the system pdf over the complete DR. In Figure 2, the area of system pdf over the common range $\left(A_{c r}\right)$ is equal to the probability of success $p_{i}$ (Suh 1990). Therefore, the IC value can be expressed as follows:

$$
I C_{i}=\log _{2}\left(\frac{1}{\mathrm{~A}_{\mathrm{cr}}}\right) .
$$

When the available information is not precisely expressed in terms of crisp values, but it is expressed imprecisely in terms of linguistic variables, the $\mathrm{AD}$ theory can then be adapted

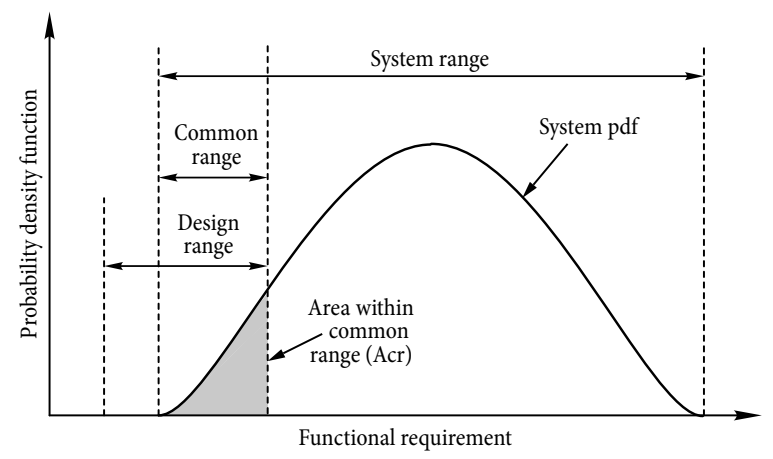

Fig. 2. Design range, system range, common range and system pdf for a FR 
in its fuzzy form to solve the design or decision-making problem (Cebi, Kahraman 2010). Fuzzy set theory (Zadeh 1965) was developed to handle imprecise information in an efficient manner to arrive at the logical conclusions in a more scientific manner. It is used to convert imprecise linguistic terms into numerical values using triangular fuzzy numbers (TFNs) or trapezoidal fuzzy numbers (TrFNs).

Figure 3 exhibits a $\operatorname{TrFN}, \tilde{A}(\mathrm{a}, \mathrm{b}, \mathrm{c}, \mathrm{d})$ with its membership function, as given in Eq. (10).

$$
\begin{aligned}
f_{\tilde{A}}(x) & =(x-a) /(b-a), & & a \leq x \leq b \\
& =1, & & b \leq x \leq c \\
& =(x-d) /(c-d), & & c \leq x \leq d \\
& =0, & & \text { otherwise. }
\end{aligned}
$$

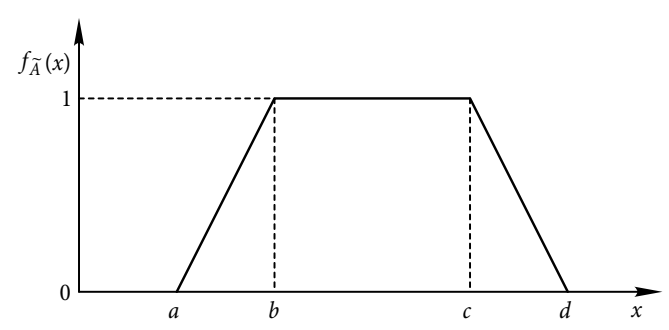

Fig. 3. Membership function of trapezoidal fuzzy number

The IC value for a considered criterion in case of FAD principles is given by Eq. (11), where the common range is the area of intersection of TrFNs representing SR and DR.

$$
I C_{i}=\log _{2}\left(\frac{\text { Area of } \mathrm{TrFN} \text { of system range }}{\text { Common range }}\right) \text {. }
$$

The basic algebraic operations of addition, subtraction, multiplication and division on two TrFNs represented as $\tilde{A}_{1}=\left(a_{1}, b_{1}, c_{1}, d_{1}\right)$ and $\tilde{A}_{2}=\left(a_{2}, b_{2}, c_{2}, d_{2}\right)$ can be expressed as follows:

Addition and subtraction: $\tilde{A}_{1} \pm \tilde{A}_{2}=\left(a_{1} \pm a_{2}, b_{1} \pm b_{2}, c_{1} \pm c_{2}, d_{1} \pm d_{2}\right)$,

Multiplication: $\tilde{A}_{1} \times \tilde{A}_{2} \cong\left(a_{1} a_{2}, b_{1} b_{2}, c_{1} c_{2}, d_{1} d_{2}\right)$, $k \times \tilde{A}_{2}=\left(k a_{2}, k b_{2}, k c_{2}, k d_{2}\right)$ where $k$ is a non-zero constant,

Division: $\frac{\tilde{A}_{1}}{\tilde{A}_{2}} \cong\left(\frac{a_{1}}{a_{2}}, \frac{b_{1}}{b_{2}}, \frac{c_{1}}{c_{2}}, \frac{d_{1}}{d_{2}}\right)$.

It is being observed that both crisp and fuzzy $\mathrm{AD}$ approaches have been pervasively utilized in major areas of applications, like product design, system design, manufacturing system design, software design and decision-making (Kulak et al. 2010). Some of the recent applications of FAD methodology in the field of decision-making are summarized as follows. Vinodh (2011) developed a hierarchical structure to model the design process of an agile production system of an Indian electronic switch manufacturing organization. 
Boran et al. (2012) evaluated various energy policies for Turkey using FAD principles. $\mathrm{Li}$ (2013) extended AD principles in intuitionistic fuzzy environment for selection of the best knowledge map design. Beng and Omar (2014) showed that FAD approach could be effective while dealing with problems concerning green supplier selection and optimization of manufacturing solution. Kannan et al. (2014) applied FAD principles to select the best green supplier for a Singapore-based plastic manufacturing company. Therefore, from the review of FAD applications, the proposed application of FAD methodology for construction project selection in the form of a SHPP seems to be a novel area and hence, worth pursuing.

\section{FAD methodology for SHPP project selection}

The procedural steps of the adopted FAD methodology for solving the considered SHPP project selection problem are briefly outlined here-in-under.

Step 1. As the construction activity of a SHPP is contemplated in this work, a committee of professionals from the Government as well as private developers of hydro-power project is therefore constituted. The committee at first identifies a group of four candidate SHPPs for further analysis.

Step 2. Various factors which govern the construction activity of the SHPP in general are then studied by the committee. Afterwards, those factors are categorized into different sets of criteria and sub-criteria. Those criteria are also classified as benefit (higher the better) and cost (smaller the better) criteria.

Step 3. As all the criteria are of qualitative nature, it is thus necessary to assess them with the help of a proper fuzzy scale. Hence, a nine point fuzzy scale is considered for critical evaluation of the alternatives with respect to the considered criteria.

Step 4. As higher values are always desired for the beneficial criteria, the ideal DR for them is chosen to vary from the least membership function of " 0 " to maximum of " 1 " respectively for minimum and maximum values of SR of alternatives, as shown in Figure 4. The reverse model is followed for cost criteria.

Step 5. The expert's committee then evaluates all the SHPP candidate alternatives using the considered fuzzy scale unanimously.

Step 6. Sub-criteria assessments are then aggregated using Eq. (12) (Kannan et al. 2014). Let $\mathrm{C}_{i 1}, \mathrm{C}_{i 2}, \mathrm{C}_{i 3}, \ldots, \mathrm{C}_{i k}$ be the sub-criteria to be aggregated into the main criterion of $\mathrm{C}_{i}$
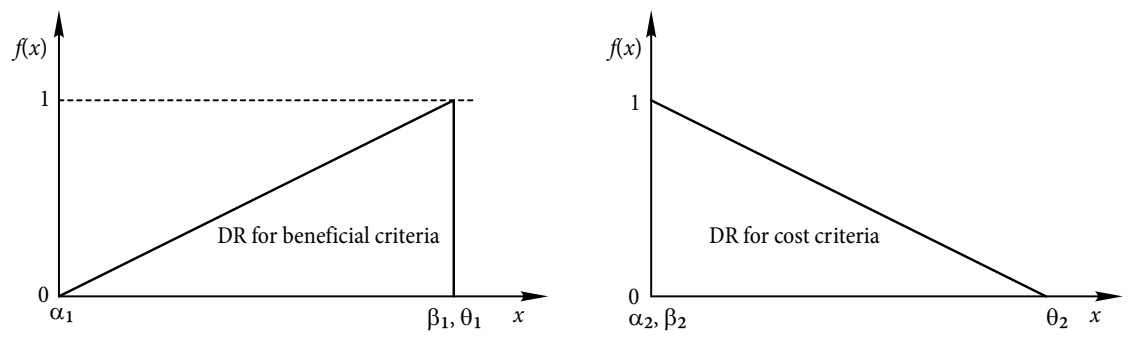

Fig. 4. Ideal design ranges for beneficial and cost criteria 
$\left(a_{i}, b_{i}, c_{i}\right)$. Therefore, the aggregated value is obtained as follows:

$$
\mathrm{C}_{i}=\frac{\left(\mathrm{C}_{i 1}+\mathrm{C}_{i 2}+\mathrm{C}_{i 3}+\ldots+\mathrm{C}_{i k}\right)}{k}=\left(a_{i}, b_{i}, c_{i}\right),
$$

where $k$ is the number of sub-criteria.

Step 7. Individual IC values for all the criteria are calculated applying Eq. (11) and are added up to derive the total IC value for each alternative.

Step 8. Total IC values of all the SHPP project alternatives are arranged in ascending order for subsequent ranking.

\section{Illustrative example}

Depending on the character of the actual facility being constructed, construction projects can be broadly classified as simply residential building construction, commercial building construction, industrial construction and heavy civil construction projects. Industrial construction projects include power plants, manufacturing plants, solar and wind farms, refineries etc. From the category of power plants, four SHPPs of 25MW generation capacity, to be located at different geographical sites in India, are considered here for analysis so as to select the best feasible plant for commencing the construction activity. As already cited out in this paper, selection of construction projects is generally affected by many independent as well as interactive criteria. Therefore, in order to analyze the suitability of these four SHPPs, seven criteria, such as technical feasibility $\left(C_{1}\right)$, approachability $\left(C_{2}\right)$, constructability $\left(\mathrm{C}_{3}\right)$, legal and environmental impact assessment $\left(\mathrm{C}_{4}\right)$, risk/return ratio $\left(\mathrm{C}_{5}\right)$, socio-economic climate $\left(\mathrm{C}_{6}\right)$, purchasing and feed-in tariffs $\left(\mathrm{C}_{7}\right)$ are considered. The criterion of technical feasibility $\left(\mathrm{C}_{1}\right)$ is further sub-divided into water head availability $\left(\mathrm{C}_{11}\right)$ and availability of technical manpower $\left(\mathrm{C}_{12}\right)$ in order to clearly distinguish between the considered alternatives. The relevance of each of these criteria with reference to the construction of SHPPs is explained as below.

Technical feasibility $\left(\mathrm{C}_{1}\right)$ - The first and foremost requirement for setting up a SHPP of $25 \mathrm{MW}$ generation capacity is the water availability. The SHPPs are either run-of-the river type or dam based, depending on the topography of the selected site. The objective of a SHPP is to convert the energy of flowing water of rivers, canals and streams, with a certain fall, called "head", into electric energy. The amount of electric power generated is proportional to the flow and head of water. Therefore, depending on the available hydrological data, a judicious mix of water head and water discharge is to be achieved for maximum power generation. It is also always beneficial to have the local availability of technical manpower required for operation and maintenance of SHPPs, as those are located in hilly and isolated regions.

Approachability $\left(\mathrm{C}_{2}\right)$ - Generally, the SHPPs are site specific and located in remote areas, and the availability of adequate access and evacuation infrastructure become the major issues to be looked into before actual implementation of the project. Many times, the basic infrastructure, such as roads, bridges and transmission lines from the plant site to the 
nearest motorable road/grid station need to be built by the private developers themselves which increases both the gestation period as well as cost/MW of the power generated.

Constructability $\left(\mathrm{C}_{3}\right)$ - The geological structure of the construction site of the SHPP should be seismically stable so that it is least affected by the natural calamities, like flash floods, landslides and earthquakes. In order to sustain the weight of dam and water stored in the dam, the rock structure at the site of dam should be strong enough.

Legal and environmental impact assessments $\left(\mathrm{C}_{4}\right)$ - There are some key environmental legislations and guidelines issued by the government for the prevention and control of water, air pollution; to halt India's rapid deforestation; to protect wildlife and so on. It is mandatory on the part of the project developers to comply with these legal aspects prior to getting the permission for the SHPP construction project. The overall effects of construction and further operation of a SHPP on the environment can be categorized both as positive (favourable) as well as negative (undesirable) in nature. Some of the positive environmental impacts can be listed as checking deforestation which is taking place to meet fodder and fuel demands in remote areas, improved ground water table, less $\mathrm{CO}_{2}$ emission, less impact on flora and fauna etc. On the other hand, due to various activities related with the SHPP as construction of dam, approach roads, diversion tunnel, channel, transmission line and also due to ponding, peaking operation of power station, there are many adverse effects. Some of these negative environmental effects can be listed as submergence of agricultural and forest land, submergence of human settlement and displacement of population, change in aquatic plant life and fish species, high water evaporation rate etc. It should be the endeavor of the planners/developers to identify those negative environmental impacts and try to mitigate them. Therefore, following the principle of lesser the better, in the analysis of the selected problem, this criterion is considered as a non-beneficial attribute, with focus on reducing its negative impact on the SHPPs.

Risk/return ratio $\left(\mathrm{C}_{5}\right)$ - The successful construction, operation and further constant yields from a SHPP depend on many environmental as well as man-made factors. Environmental factors include the vagaries of nature, such as seismic activities, floods, reduced water supply, siltation of water basin, landslides etc. Man-made factors include the fluid political situations, workers' unrest and diversion of water upstream for irrigation or other uses and so on. Therefore, an assessment of the risk/return ratio for each project is vital for determining its feasibility. Usually, a project which entails higher risk guarantees a higher return. It is considered as a non-beneficial criterion with its desired value on the lower side.

Socio-economic climate $\left(\mathrm{C}_{6}\right)$ - Sometimes, the SHPP developers face objections from the local community. Normally, the issues are related to acquisition of land, employment of local people and contribution towards local area development. To address these issues, the concerned State Governments have specific provisions in their policies and some obligatory measures to be complied by the project developers.

Purchasing and feed-in tariffs $\left(\mathrm{C}_{7}\right)$ - The SHPPs are mostly constructed in the hilly and remote areas. Therefore, profitability of the SHPP depends on whether the power being generated is purchased and if so, at what tariff. As regards rates, there should either be a state-guaranteed minimum feed-in tariff or the possibility of selling the power to stateowned or private utilities. 
All these seven criteria for evaluation and selection of SHPP projects cannot be expressed precisely in crisp terms and hence, a fuzzy scale consisting of linguistic terms is chosen to express them for all the four alternatives. In order to be more realistic in evaluation, the fuzzy scale considered is expansive in nature, consisting of 9 points as very poor $(\mathrm{VP})$, between very poor and poor (B. VP and $\mathrm{P})$, poor $(\mathrm{P})$, between poor and fair $(\mathrm{B} . \mathrm{P}$ and $F$ ), fair (F), between fair and good (B. F and $G)$, good $(G)$, between good and very good (B. G and VG), very good (VG) (Chou et al. 2008). These linguistic ratings of VP, B. VP and P, P, B. P and F, F, B. F and G, G, B. G and VG, and VG are respectively assigned with the TrFNs as $(0,0,0,2),(0,0,2,4),(0,2,2,4),(0,2,5,7),(3,5,5,7),(3,5,8,10),(6,8$, $8,10),(6,8,10,10),(8,10,10,10)$. By employing this fuzzy scale, the experts' committee evaluates the four SHPPs with respect to all the criteria and these evaluations represent the SR data, as shown in Table 1.

As discussed in FAD methodology, if a given alternative completely satisfies the decision goal, then the value of IC becomes " 0 "; whereas, if the given alternative does not satisfy the decision goal at all, then the corresponding value of IC is "infinite". These extreme cases form a kernel (Kahraman, Çebı 2009), i.e. there does not exist any dominance among these alternatives. To avoid this situation and make it possible to rank the alternatives, the ideal DR values for beneficial criteria and cost criteria are taken as represented by TFNs, $\left(\alpha_{1}, \beta_{1}\right.$, $\left.\theta_{1}\right)$ and $\left(\alpha_{2}, \beta_{2}, \theta_{2}\right)$ respectively, and are depicted in Figure 4. These TFNs are respectively $(0,10,10)$ and $(0,0,10)$.

Using Eq. (12), two sub-criteria, i.e. $\mathrm{C}_{11}$ and $\mathrm{C}_{12}$ are aggregated to obtain the resultant values of the first criterion of technical feasibility $\left(C_{1}\right)$ for all the alternatives. Along with these, the SR data of all other criteria, represented in terms of TrFNs, are shown collectively in Table 2. In order to calculate the IC value of the alternatives, criteria $C_{1}, C_{2}, C_{3}, C_{6}$ and $C_{7}$ are considered as beneficial criteria and hence, the ideal DR for these criteria is $(0,10,10)$. The ideal DR for $\mathrm{C}_{4}$ and $\mathrm{C}_{5}$ criteria is considered as $(0,0,10)$ as they are the non-beneficial attributes. For the demonstration purpose, the IC value for alternative $\mathrm{SHPP}_{4}$, representing its performance with respect to technical feasibility criterion $\left(C_{1}\right)$, is shown calculated here with reference to Figure 5. In this figure, the triangular area PQR represents the DR, the trapezoidal area ABCR denotes the SR and the shaded portion ADER represents the CR. Using the membership functions of $\operatorname{TrFN}$ as represented in Eq. (10), the co-ordinates of the intersecting points $\mathrm{D}$ and $\mathrm{E}$ are calculated as $(6.88,0.69)$ and $(9.09,0.91)$ respectively. The area of CR is then calculated to be equal to 2.66 sq. units. The trapezoidal SR area is 3.0 sq. units. Therefore, by applying Eq. (11), the IC value of $\mathrm{SHPP}_{4}$ for criterion $\mathrm{C}_{1}$ is estimated as 0.1763 . This procedure is followed for evaluating the performance of all SHPPs with respect to every individual criterion and the resulting IC values are shown in Table 3 . The total IC value is then obtained for each alternative by summing up the individual IC values for all the criteria. It is observed from Table 3 that the FAD methodology is quite capable of evaluating the performance of all the SHPP project alternatives with respect to each and every criterion in terms of a certain and definite IC value. For alternative $\mathrm{SHPP}_{4}$, the SR of socio-economic climate criterion $\left(\mathrm{C}_{6}\right)$ is well within the DR value and hence, the corresponding IC value is zero. Among the four considered alternatives, the total IC value of $\mathrm{SHPP}_{3}$ is the least and hence, it is the best choice as a construction project for the developer. 
Table 1. Evaluation of SHPPs

\begin{tabular}{|c|c|c|c|c|c|c|c|c|}
\hline \multirow{2}{*}{$\begin{array}{l}\text { Alterna- } \\
\text { tive }\end{array}$} & \multicolumn{2}{|c|}{$\mathrm{C}_{1}$} & \multirow{2}{*}{$\mathrm{C}_{2}$} & \multirow{2}{*}{$\mathrm{C}_{3}$} & \multirow{2}{*}{$\mathrm{C}_{4}$} & \multirow{2}{*}{$\mathrm{C}_{5}$} & \multirow{2}{*}{$\mathrm{C}_{6}$} & \multirow{2}{*}{$\mathrm{C}_{7}$} \\
\hline & $\mathrm{C}_{11}$ & $\mathrm{C}_{12}$ & & & & & & \\
\hline SHPP $_{1}$ & $\mathrm{~F}$ & $\mathrm{~F}$ & $\mathrm{~F}$ & B.F \& G & $\mathrm{P}$ & VG & B.F \& G & $\mathrm{F}$ \\
\hline $\mathrm{SHPP}_{2}$ & $\mathrm{G}$ & $\mathrm{G}$ & B.F\&G & $\mathrm{G}$ & B.G\&VG & B.G\&VG & $\mathrm{G}$ & $\mathrm{G}$ \\
\hline $\mathrm{SHPP}_{3}$ & VG & B.G \& VG & $\mathrm{G}$ & $\mathrm{F}$ & $\mathrm{G}$ & $\mathrm{F}$ & B.G\&VG & G \\
\hline $\mathrm{SHPP}_{4}$ & B.F\& G & VG & B.G \& VG & $\mathrm{P}$ & $\mathrm{F}$ & G & VG & B.G \& VG \\
\hline
\end{tabular}

Table 2. SR data in terms of TrFNs

\begin{tabular}{cccccccc}
\hline $\begin{array}{c}\text { Alterna- } \\
\text { tive }\end{array}$ & $\mathrm{C}_{1}$ & $\mathrm{C}_{2}$ & $\mathrm{C}_{3}$ & $\mathrm{C}_{4}$ & $\mathrm{C}_{5}$ & $\mathrm{C}_{6}$ & $\mathrm{C}_{7}$ \\
\hline $\mathrm{SHPP}_{1}$ & $(3,5,5,7)$ & $(3,5,5,7)$ & $(3,5,8,10)$ & $(0,2,2,4)$ & $(8,10,10,10)$ & $(3,5,8,10)$ & $(3,5,5,7)$ \\
\hline $\mathrm{SHPP}_{2}$ & $(6,8,8,10)$ & $(3,5,8,10)$ & $(6,8,8,10)$ & $(6,8,10,10)$ & $(6,8,10,10)$ & $(6,8,8,10)$ & $(6,8,8,10)$ \\
\hline $\mathrm{SHPP}_{3}$ & $(7,9,10,10)$ & $(6,8,8,10)$ & $(3,5,5,7)$ & $(6,8,8,10)$ & $(3,5,5,7)$ & $(6,8,10,10)$ & $(6,8,8,10)$ \\
\hline $\mathrm{SHPP}_{4}$ & $(5.5,7.5,9,10)$ & $(6,8,10,10)$ & $(0,2,2,4)$ & $(3,5,5,7)$ & $(6,8,8,10)$ & $(8,10,10,10)$ & $(6,8,10,10)$ \\
\hline
\end{tabular}

Table 3. Selection and ranking of SHPPs

\begin{tabular}{cccccccccc}
\hline Alternative & $\mathrm{IC}_{\mathrm{C} 1}$ & $\mathrm{IC}_{\mathrm{C} 2}$ & $\mathrm{IC}_{\mathrm{C} 3}$ & $\mathrm{IC}_{\mathrm{C} 4}$ & $\mathrm{IC}_{\mathrm{C} 5}$ & $\mathrm{IC}_{\mathrm{C} 6}$ & $\mathrm{IC}_{\mathrm{C} 7}$ & $\mathrm{IC}_{\mathrm{TOTAL}}$ & Rank \\
\hline $\mathrm{SHPP}_{1}$ & 0.4352 & 0.4352 & 0.4723 & 0.0614 & 2.585 & 0.4723 & 0.4352 & 4.8966 & 3 \\
\hline $\mathrm{SHPP}_{2}$ & 0.0614 & 0.4723 & 0.0614 & 2.1699 & 2.1699 & 0.0614 & 0.0614 & 5.0577 & 4 \\
\hline $\mathrm{SHPP}_{3}$ & 0.0458 & 0.0614 & 0.4352 & 1.585 & 0.4352 & 0.1255 & 0.0614 & 2.7495 & 1 \\
\hline $\mathrm{SHPP}_{4}$ & 0.1763 & 0.1255 & 1.585 & 0.4352 & 1.585 & 0 & 0.1255 & 4.0325 & 2 \\
\hline
\end{tabular}

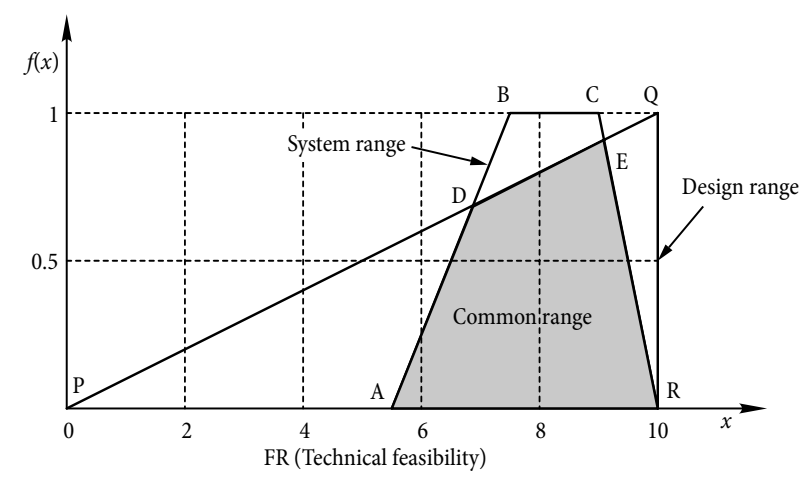

Fig. 5. SR, DR and CR for technical feasibility criterion of $\mathrm{SHPP}_{4}$

\section{Conclusions}

With the ever-increasing power needs of a populous nation, it is quite befitting to explore the renewable energy sources for their growth and sustainable development in all the spheres of life. Hydro-power, being one of the important renewable energy sources, has its abundance potential in the form of SHPPs to be spread across the country. Therefore, 
in this paper, a problem of strategically selecting the most feasible and profitable SHPP construction project is considered, as it ensures optimal resource utilization and greater contribution towards the organization's missions and goals. In the presented case study, the experts' committee identifies four SHPPs in different geographical locations of the country and also decides on a set of seven distinguishing criteria for their effective evaluation. All these criteria being of environmental, techno-commercial and socio-economic nature, are expressed subjectively for better elucidation of the said construction project. Using a 9 point fuzzy scale of TrFNs for representing the subjective data, it becomes quite effective to tap the impreciseness in the data.

In FAD methodology, the capability of the alternatives to fulfil the desired goals is expressed in terms of their total IC values as given by the fuzzy information axiom. In this paper, the DRs of beneficial as well as cost criteria are set to vary uniformly over the entire range of system capabilities, thus avoiding the chances of overall or abrupt rejection of any alternative in case of infinitive IC value. As a result of application of this scientific and rational fuzzy methodology, $\mathrm{SHPP}_{3}$ is found to be the best choice as a construction project, with others in the preference order of $\mathrm{SHPP}_{4}-\mathrm{SHPP}_{1}-\mathrm{SHPP}_{2}$. This methodology provides not only the rankings of SHPP alternatives under the overall goal, but also a measure of relative capability of each alternative with respect to each criterion in terms of its IC value. This distinctive feature helps the project managers to analyze the advantages and disadvantages of the alternative SHPPs clearly and easily, so as to adequately justify the decision-making process. Although the application of FAD methodology is explained through a representative selection of SHPP construction project, it can be applied universally across various project selection problems, with considerable research in each application area.

\section{References}

Bagocius, V.; Zavadskas, E. K.; Turskis, Z. 2014. Sequence determining of construction of the offshore wind farm construction applying permutation method, $E \& M$ Ekonomie a Management 17(3): $50-61$.

Beng, L. G.; Omar, B. 2014. Integrating axiomatic design principles into sustainable product development, International Journal of Precision Engineering and Manufacturing - Green Technology 1(2): 107-117.

Boran, F. E.; Boran, K.; Dizdar, E. 2012. A fuzzy multi criteria decision making to evaluate energy policy based on an information axiom: a case study in Turkey, Energy Sources, Part B: Economics, Planning, and Policy 7(3): 230-240. http://dx.doi.org/10.1080/15567240902839294

Cebi, S.; Kahraman, C. 2010. Extension of axiomatic design principles under fuzzy environment, Expert Systems with Applications 37(3): 2682-2689. http://dx.doi.org/10.1016/j.eswa.2009.08.010

Chen, Y. Q.; Liu, J. Y.; Li, B.; Lin, B. 2011. Project delivery system selection of construction projects in China, Expert Systems with Applications 38(5): 5456-5462.

http://dx.doi.org/10.1016/j.eswa.2010.10.008

Cheng, E. W. L.; Li, H. 2005. Analytic network process applied to project selection, Journal of Construction Engineering and Management 131(4): 459-466.

http://dx.doi.org/10.1061/(ASCE)0733-9364(2005)131:4(459) 
Chou, S. Y.; Chang, Y. H.; Shen, C. Y. 2008. A fuzzy simple additive weighting system under group decision-making for facility location selection with objective/subjective attributes, European Journal of Operational Research 189(1): 132-145. http://dx.doi.org/10.1016/j.ejor.2007.05.006

Contreras, A. V.; Serrano, M. D.; Quevedo, R. A.; Pérez, J. S. 2012. The importance of geological and geophysical exploration costs in the construction of hydroelectric dams - comparative examples in Mexico, International Journal of Research and Reviews in Applied Sciences 12(3): 438-448.

Dey, P. K. 2006. Integrated project evaluation and selection using multiple-attribute decision-making technique, International Journal of Production Economics 103(1): 90-103. http://dx.doi.org/10.1016/j.ijpe.2004.11.018

Ebrahimnejad, S.; Mousavi, S. M.; Tavakkoli-Moghaddam, R.; Hashemi, H.; Vahdani, B. 2012. A novel two-phase group decision making approach for construction project selection in a fuzzy environment, Applied Mathematical Modelling 36(9): 4197-4217.

http://dx.doi.org/10.1016/j.apm.2011.11.050

Han, S. H.; Diekmann, J. E.; Ock, J. H. 2005. Contractor's risk attitudes in the selection of international construction projects, Journal of Construction Engineering and Management 131(3): 283-292. http://dx.doi.org/10.1061/(ASCE)0733-9364(2005)131:3(283)

Hernández, C.; Pajares, J.; Paredes, A. L. 2011. A portfolio inspired metric for project selection in construction management, Organization, Technology and Management in Construction - An International Journal 3(1): 264-268.

Kahraman, C.; Çebı, S. 2009. A new multi-attribute decision making method: hierarchical fuzzy axiomatic design, Expert Systems with Applications 36(3-Part 1): 4848-4861.

Kannan, D.; Govindan, K.; Rajendran, S. 2014. Fuzzy axiomatic design approach based green supplier selection: a case study from Singapore, Journal of Cleaner Production 96: 194-208. http://dx.doi.org/10.1016/j.jclepro.2013.12.076

KarimiAzari, A.; Mousavi, N.; Mousavi, S. F.; Hosseini, S. B. 2011. Risk assessment model selection in construction industry, Expert Systems with Applications 38(8): 9105-9111. http://dx.doi.org/10.1016/j.eswa.2010.12.110

Kulak, O.; Cebi, S.; Kahraman, C. 2010. Applications of axiomatic design principles: a literature review, Expert Systems with Applications 37(9): 6705-6717. http://dx.doi.org/10.1016/j.eswa.2010.03.061

Li, M. 2013. Extension of axiomatic design principles for multicriteria decision making problems in intuitionistic fuzzy environment, Mathematical Problems in Engineering, Article ID 813471. http://dx.doi.org/10.1155/2013/813471

Mojahed, M.; Yusuff, R. M.; Reyhani, M. 2010. Determining and ranking essential criteria of construction project selection in telecommunication of North Khorasan - Iran, International Journal of Environmental Science and Development 1(1): 79-84. http://dx.doi.org/10.7763/IJESD.2010.V1.16

Naaranoja, M.; Kähkönen, K.; Keinänen, M. 2014. Construction projects as research objects - different research approaches and possibilities, Procedia - Social and Behavioral Sciences 119: 237-246. http://dx.doi.org/10.1016/j.sbspro.2014.03.028

Panić, M.; Urošev, M.; Pešić, A. M.; Brankov, J.; Bjeljac, Ž. 2013. Small hydropower plants in Serbia: hydropower potential, current state and perspectives, Renewable and Sustainable Energy Reviews 23: 341-349. http://dx.doi.org/10.1016/j.rser.2013.03.016

Puthamont, S.; Charoenngam, C. 2007. Strategic project selection in public sector: construction projects of the ministry of defence in Thailand, International Journal of Project Management 25(2): 178-188. http://dx.doi.org/10.1016/j.ijproman.2006.05.001

Rejment, M.; Dziadosz, A. 2014. Selected aspects of construction projects selection including risk estimation, Technical Transactions, Civil Engineering 1-B: 221-228.

Rikhtegar, N.; Mansouri, N.; Oroumieh, A. A.; Yazdani-Chamzini, A.; Zavadskas, E. K.; Kildienė, S. 2014. Environmental impact assessment based on group decision-making methods in mining projects, Economic Research - Ekonomska Istrazivanja 27(1): 378-392. 
Rouyendegh, B. D. 2012. Evaluating projects based on intuitionistic fuzzy group decision making, Journal of Applied Mathematics, Article ID-824265. http://dx.doi.org/10.1155/2012/824265

Siozinyte, E.; Antucheviciene, J.; Kutut, V. 2014. Upgrading the old vernacular building to contemporary norms: multiple criteria approach, Journal of Civil Engineering and Management 20(2): 291-298. http://dx.doi.org/10.3846/13923730.2014.904814

Staniūnas, M.; Medineckienė, M.; Zavadskas, E. K.; Kalibatas, D. 2013. To modernize or not: ecologicaleconomical assessment of multi-dwelling houses modernization, Archives of Civil and Mechanical Engineering 13(1): 88-98. http://dx.doi.org/10.1016/j.acme.2012.11.003

Streimikiene, D. 2013. Assessment of energy technologies in electricity and transport sectors based on carbon intensity and costs, Technological and Economic Development of Economy 19(4): 606-620. http://dx.doi.org/10.3846/20294913.2013.837113

Suh, N. P. 1990. The principles of design. New York: Oxford University Press.

Suh, N. P. 2001. Axiomatic design: advances and applications. New York: Oxford University Press.

Taylan, O.; Bafail, A. O.; Abdulaal, R. M. S.; Kabli, M. R. 2014. Construction projects selection and risk assessment by fuzzy AHP and fuzzy TOPSIS methodologies, Applied Soft Computing 17: 105-116. http://dx.doi.org/10.1016/j.asoc.2014.01.003

Turskis, Z.; Zavadskas, E. K.; Kutut, V. 2013. Model based on ARAS-G and AHP methods for multiple criteria prioritizing of heritage value, International Journal of Information Technology \& Decision Making 12(1): 45-73. http://dx.doi.org/10.1142/S021962201350003X

Vinodh, S. 2011. Axiomatic modelling of agile production system design, International Journal of Production Research 49(11): 3251-3269. http://dx.doi.org/10.1080/00207543.2010.481295

Vodopivec, B.; Žarnic, R.; Tamošaitienè, J.; Lazauskas, M.; Šelih, J. 2014. Renovation priority ranking by multi-criteria assessment of architectural heritage: the case of castles, International Journal of Strategic Property Management 18(1): 88-100. http://dx.doi.org/10.3846/1648715X.2014.889771

Wang, J.; Xu, Y.; Li, Z. 2009. Research on project selection system of pre-evaluation of engineering design project bidding, International Journal of Project Management 27(6): 584-599. http://dx.doi.org/10.1016/j.ijproman.2008.10.003

Weissenböck, S.; Girmscheid, G. 2014. Project selection regarding life-cycle oriented and equity-intensive projects: a critical assessment of the PPP project selection process in the construction industry, in J. Crittenden, C. Hendrickson, B. Wallace (Eds.). Proceedings of the 2014 International Conference on Sustainable Infrastructure, ICSI 2014: Creating Infrastructure for a Sustainable World, 6-8 November 2014, Long Beach, California. ASCE, 377-387.

Wu, Y.; Geng, S.; Xu, H.; Zhang, H. 2014. Study of decision framework of wind farm project plan selection under intuitionistic fuzzy set and fuzzy measure environment, Energy Conversion and Management 87: 274-284. http://dx.doi.org/10.1016/j.enconman.2014.07.001

Zadeh, L. A. 1965. Fuzzy sets, Information and Control 8(3): 338-353. http://dx.doi.org/10.1016/S0019-9958(65)90241-X

Zavadskas, E. K.; Antucheviciene, J.; Saparauskas, J.; Turskis, Z. 2013. MCDM methods WASPAS and MULTIMOORA: verification of robustness of methods when assessing alternative, Economic Computation and Economic Cybernetics Studies and Research 47(2): 5-20.

Zavadskas, E. K.; Vilutiene, T.; Turskis, Z.; Šaparauskas, J. 2014. Multi-criteria analysis of Projects' performance in construction, Archives of Civil and Mechanical Engineering 14(1): 114-121. http://dx.doi.org/10.1016/j.acme.2013.07.006

Zelenakova, M.; Zvijakova, L.; Purcz, P. 2013. Small hydro power plant - Environmental impact assessment - Case study, International Journal of Emerging Technology and Advanced Engineering 3(4): 35-42. 
Anant V. KHANDEKAR is working as a Senior lecturer at Government Polytechnic, Mumbai (India). He graduated in Mechanical Engineering from Government College of Engineering, Amravati, Maharashtra (India) in 1989. He obtained his Masters in Manufacturing Technology from Thapar Institute of Engineering and Technology, Patiala (India) in 2002. He has published few papers in journals of international repute as well as presented his work in some conferences. At present, he is pursuing his $\mathrm{PhD}$ (Engg) research work at Jadavpur University, Kolkata (India) and his research interests include the applications of fuzzy multi-criteria decision-making techniques in manufacturing environment.

Jurgita ANTUCHEVIČIENĖ is Doctor, Professor at the Department of Construction Technology and Management, Vilnius Gediminas Technical University, Vilnius, Lithuania. She is a member of EURO Working Groups Multicriteria Decision Aiding and OR in Sustainable Development and Civil Engineering, Editorial Board member of three international research journals. Her research interests include sustainable development, construction business management and investment, multiple criteria analysis, decision-making theories and decision support systems.

Shankar CHAKRABORTY is an Associate Professor in Production Engineering Department of Jadavpur University. He had been graduated in 1986 from University of Calcutta and obtained his postgraduate degree from Jadavpur University in 1989. He had been awarded with PhD (Engg.) from Jadavpur University in 1994. His research interests are in the areas of applications of different multicriteria decision-making methods in manufacturing environment, control chart pattern recognition, and development of MIS and ERP systems for engineering applications. He has guided several ME and $\mathrm{PhD}$ (Engg.) theses, and published numerous papers in international journals. He is a regular reviewer of several international journals. 